cusses health and safety and trade unions rights in the nuclear industry, and points to the need for more information. Consideration is then given to jobs, energy and industrial strategy, and alternative policy options of the kind recently detailed by Gerald Leach et al. in their report $A$ Low Energy Strategy for the UK (Science Reviews Ltd and IIED: London, £7.50; for review, see Nature 277, 162; 1979). According to Elliott, "Because the alternative technologies are mainly, by their nature, decentralised they can support a decentralised society, based on community and workers' control. But their introduction into society as it is clearly doesn't necessarily guarantee that such a state of affairs will come about". However, Elliott concludes, "The fight for alternative technologies is not an alternative to the fight for socialism. It can and should be part of it"-a sentiment making up in vigour what it lacks in grace. Part three of the book discusses how such aims can be pursued, by trade unionists and environmentalists working for common objectives.

All four authors write clear, readable prose, in language which is accessible

\section{Peer review in the NSF}

\section{S. S. Blume}

Peer Review in the National Science Foundation: Phase One of a Study. By the National Research Council. Pp. 193. (National Academy of Sciences: Washington, DC, 1978.) \$10.75.

Most readers of Nature will be well aware that the peer review system (the system by which research grant applications are evaluated by experts in the disciplines concerned) has recently been subjected to considerable criticism in the USA. Members of the general public as well as congressmen have attacked an 'old boy network' said to have control of research funds. The National Science Foundation has steadfastly refused to make confidential referees' reports (and their names) available to members of congress, and this has been held to be a concealment of the Foundation's biased procedures. Politicians have also accused the Foundation of giving inadequate weight to the needs of society (as distinct from those of science) in the selection of projects for funding, and and blessedly low in jargon. However, it is a pity that more attention was not paid to fine detail; too many trifling but irritating errors of fact have survived into print. (There are eleven British Magnox stations in all, not twelve, including a total of 26 reactors; there is no power reactor in Denmark, only three small research reactors; Belgium, far from being a nuclear "poor relation", has three substantial power reactors already in operation and four more under construction, and generates a larger percentage of its electricity by nuclear power than any other country; the proposed commercial fast reactor would be 1,000 $\mathrm{MW}$, not $100 \mathrm{MW}$; and so on.) It would be easy to correct virtually all these fluffs in a second printing. To do so would remove the most irksome blemish on what is otherwise a very useful book, one which deserves to be widely read and discussed, by trade unionists, environmentalists, and all those other 'ists who make up our disputatious society.

Walt Patterson is Energy Consultant to Friends of the Earth (London) Ltd.

of discriminating against scientists in less prestigious institutions: The fault, some claim, lies in the peer review system. Ripples of these criticismsthe view that justice should not only be done but be seen to be done, that criteria of equity applicable in other areas of public resource-allocation should apply also in science-have reached these shores. For example, not long ago the UK Research Councils had to consider the claim that they dealt unfairly with scientists working in polytechnics.

This volume reports on the first stage of a study of the operation of the peer review system in the NSF, commissioned by the National Academy of Sciences. The researchers were given full access to reports and files on all applications to the Foundation. They interviewed programme directors (who unlike British committee secretaries have final responsibility for deciding which applications in their field get funded). In the study the authors focus particularly upon three things: How are reviewers (referees) chosen? How do the referees respond to various characteristics of the applicant other than their assessment of the quality of his (very rarely her!) application? And how does the final decision (that is, of the programme director) relate to the referees' assessments?

The study provides no ammunition to the critics of science. An effective combination of statistical and qualitative analysis is used to show, most simply, that the best research gets funded. No evidence for an old boy network is uncovered, and findings suggest that referees are not much in. fluenced by the status of the applicant's institutional affiliation, or by his seniority, or by whether he has or has not recently had a Foundation grant. They simply judge the application on its merits. Moreover, it seems to be these evaluations which do largely determine what gets funded. To be sure, if one tabulates 'successful' compared with 'unsuccessful' applications by extraneous variables such as those suggested above, one finds clear differences. But all of these vanish when reviewer's evaluation is introduced. Of course there are curiosities. A not infrequent one seems to be the eminent scientist whose application is rejected because it consists of little more than "I'm me-give me the money"! So the system seems to work as intended, and this study shows this to be so.

Nevertheless, as I am sure both authors and sponsors appreciate, the study will not silence the critics. It is not simply that the 'enemies' of science are unsusceptible to reason (though one wouldn't really expect them to succumb to a piece of applied social research). It is also because the study does not-perhaps could not-tackle all the criticisms made. For example, referees are required by the NSF to consider an application in the light of criteria reflecting the competence of the investigator, the scientific merit of the project, its relevance and utility, and its broad implications for American science and science education. The brief section of the report devoted to the problem of weighting these considerations against each other is all too sketchy, and will hardly persuade the cynic that much attention is paid to questions of practical applicability. One gets no feel for this at all. The critic can still claim that if the scientist from a poor southern college is 'fairly' treated, that is not enough. After all, positive discrimination in favour of the disadvantaged is an accepted feature of many areas of policy-why not in science? And even the favourably disposed but budget-conscious politician may feel uneasy in defending a government agency which makes "no systematic attempt to monitor the outcomes of research grants" (p. 158)-that is, to see how its money was spent.

But perhaps for the reviewer to attack a methodical piece of research for failing to resolve an essentially political dispute is not only naive, but inappropriately partisan.

Stuart Blume is in the Department of Social Science and Administration, London School of Economics, University of London, UK. 